\title{
Nonconceptualism and the Cognitive Impenetrability of Early Vision
}

Josefa Toribio

ICREA - Universitat Autònoma de Barcelona

\begin{abstract}
This paper examines the relationship between cognitive impenetrability and perceptual nonconceptualism. I argue against the view, recently defended by Raftopoulos, that the (alleged) cognitive impenetrability of early vision is a necessary and sufficient condition for states of early vision and their content to be nonconceptual. I show that that view, here dubbed 'the mutually entailing thesis', admits two different standard interpretations depending on how we understand the property of being nonconceptual - corresponding to the distinction between the state and the content views of perceptual nonconceptualism. I first argue for the falsity of the state-nonconceptualist reading of the mutually entailing thesis, on the grounds that it mistakenly takes being nonconceptual to be a causal instead of a constitutive relationship. The content-nonconceptualist understanding of the thesis, I then argue, is disproved by plausible views regarding the content of experience. The mutually entailing thesis could only be true, I conclude, on a non-standard, causal interpretation of the notion of nonconceptual content. Yet, on that reading, the thesis would either be trivially true or would entirely fail to engage with the contemporary literature on perceptual nonconceptualism.
\end{abstract}

\section{Introduction}

My aim in this paper is to explore the relationship between two theses about perceptual processing and its contents. The first thesis is that early vision is cognitively impenetrable. This empirical claim amounts to denying that either early visual information processing itself or its output can be directly causally influenced by prior cognitive states, including background beliefs, goals, affective states and tacit knowledge (Pylyshyn, 1980; 1984; 1999). Early vision is, in Fodor's (1983) term, informationally encapsulated or, as it will be characterized here, cognitive impenetrable. The second, philosophical, thesis - perceptual nonconceptualism - is that the personal-level content of perceptual experiences, i.e., how we consciously represent the world in perception, does not involve concepts. ${ }^{1}$ 
It has recently been argued that these two theses are mutually entailing: that the (alleged) cognitive impenetrability ( $C I$ henceforth) of early vision is a necessary and sufficient condition for perceptual nonconceptualism about states of early vision and their content (Raftopoulos, 2009; Raftopoulos \& Müller, 2006; Raftopoulos, 2013). Raftopoulos' (2013) is entirely dedicated to the defence of this claim, i.e., to defending the view that, on the assumption that all and only early vision is cognitively impenetrable, "the CI of a state and content is a sufficient and necessary condition for the state and its content to be purely NCC, the CI $\equiv$ NCC thesis" (Raftopoulos, 2013, p. 1). ${ }^{2}$ In what follows, I will refer to Raftopoulos' CI $\equiv$ NCC thesis as the mutually entailing thesis (MET henceforth). ${ }^{3}$ According to $M E T, C I$ is true if and only if perceptual nonconceptualism is true of early vision states and their content. In this paper I argue that no such relationship of necessity or sufficiency holds between the two theses.

It is important to acknowledge from the start that both the evidence and type of considerations that could be brought to bear on the plausibility of MET will depend on whether it is supposed to be a conceptual truth, such as 'a person is a bachelor if and only if he is an unmarried man', a contingent truth, such as 'a creature has a heart if and only if it has a kidney' or, rather its truth is supposed to be of the kind exhibited for example by the biconditional: 'a liquid is water if and only if its chemical structure is $\mathrm{H}_{2} \mathrm{O}^{\prime}$ - considered by many to be a necessary a posteriori truth. Note, first, that if $M E T$ was considered a conceptual truth, then the $C I$ of early vision and perceptual nonconceptualism would have to be treated not only as mutually entailing, but also conceptually equivalent. It is fair to assume, however, that this is not what Raftopoulos is trying to establish, since - as a conceptual truth-MET would be true, but trivially so. Its truth would be based on making 'nonconceptual' and 'cognitively impenetrable' not only coextensive, but also synonymous. ${ }^{4}$ It also seems fair to assume that MET is not intended "merely" as a contingent truth, since Raftopoulos' defence of MET alludes to and attempts to capture the motivations and considerations pertaining to the philosophical debate on perceptual nonconceptualism. ${ }^{5}$ Such a defence makes it very clear that his project is conceived as a substantial contribution to our understanding of the notion of nonconceptual content and to that philosophical debate - where the property of being nonconceptual 
is not construed in empirical but in constitutive terms. Hence, it seems appropriate to take $M E T$ as a claim intended to be an a posteriori necessity. Or, whatever one's take on the notion of a posteriori necessities, it seems appropriate to take $M E T$ as a claim of the same type as 'a liquid is water if and only if it is $\mathrm{H}_{2} \mathrm{O}$ '. In both cases, what is taken to be a necessary and sufficient condition for being something else (be it water or nonconceptual content) is a property whose instantiation is decided by empirical methods $\left(\mathrm{H}_{2} \mathrm{O}\right.$ and $\mathrm{CI}$, respectively). In each case, it is assumed that we have some pre-theoretical understanding of 'water' or 'nonconceptual'. It is just that, unlike 'water', which is a folk theoretical term, 'nonconceptual' is a theoretically sophisticated notion and its meaning has attracted a not insubstantial amount of philosophical discussion. Hence, one needs to tread carefully when assessing the plausibility of $M E T$ as a thesis involving this notion.

It is also important to notice that, in the formulation of $M E T$, the content of the output states of early vision processing is regarded as personal-level content. These early vision output states may very well be unstable, imprecise and swiftly processed; but they are taken to be experiences, albeit short-lived, of properties of which we are phenomenally aware - or so I grant the advocates of MET. My strategy will be to explore the consequences of $C I$ with regard to the nature of the personal-level content of these early vision processing output states (EVS henceforth). ${ }^{6}$

The paper is organized as follows. Section 2 provides some empirical background on visual information processing that helps spell out $C I$. Here, the causal and direct nature of the kind of influence that the notion of $C I$ rules out will be clarified. In Section 3, after clearing up some terminological issues, I show that MET admits two different standard interpretations, depending on how we understand the property of being nonconceptual - corresponding to the, by now well-known, distinction between the state and the content views of perceptual nonconceptualism (see e.g., Heck, 2000; Speaks, 2005). In Section 4, I argue that, on the state view of nonconceptualism, according to which being nonconceptual is a relational property such that the subject need not possess the concepts involved in a correct characterization of the content of their EVS, MET fails - on the grounds that it mistakenly takes being nonconceptual to be a causal instead of a constitutive relationship. In Section 5, I argue that on the stronger content view of nonconceptualism - according to which being 
nonconceptual is understood as a monadic property of the content of an EVS: the property of not being composed of concepts-MET is disproved by plausible views regarding the content of experience. Sections 4 and 5 together thus show that MET is false on either standard interpretation of 'nonconceptual', and that the CI of EVS and their content is neither a necessary nor a sufficient condition for nonconceptualism about $E V S$ or their contents to be true. Some brief, concluding remarks are then provided in the final section.

\section{Early vision information processing and EVS}

Early vision comprises both the set of mechanisms sensitive to the causal influence of low-level visual properties and the output states of the processing carried out by those mechanisms. Although somewhat dated and often seen as over simplistic, I briefly rely here on Marr's (1982) seminal work to illustrate the idea that early vision involves several levels of visual information processing, usually grouped into two: the so-called primal sketch and the $2 \frac{1}{2}-\mathrm{D}$ sketch levels. My aim is not to provide a scientifically sophisticated picture of the workings of human vision; I am merely borrowing from Marr's model as a way of bringing to the fore the existence of different levels of visual information processing within early vision. The main idea is that these primitive and mid-level processes certainly do display some of the properties that Marr's primal sketch and $2 \frac{1}{2} 2$-D sketch levels originally posited. At the primal sketch level, the raw output from the rods and cones of the retina provides a grey-scale representation. Sharp changes in the intensity of light are computed as object boundaries. Oriented edges, bars, ends and blobs are represented in terms of type, position, orientation, scale and contrast. At the 21/2-D sketch level, edges, bars, ends and blobs are integrated so as to represent the shape, orientation and depth of the visible surfaces, which are thus separated from the background. On Marr's view, at this $2 \frac{1}{2}-\mathrm{D}$ sketch level, the visual system is sensitive to the properties of motion, colour, and texture. It can also complete, in a viewer-centred coordinate system, contours that are only partially present in the input image. There is no object recognition yet, but there is phenomenology, i.e., there is a conscious, even if demonstrative, recognition of the aforementioned properties.? Object recognition does 
not take place until the processing of information reaches the 3-D sketch level, and it is based on a modular and hierarchical grouping of volumetric and surface primitives that relies on memory, knowledge and judgment. At that level, usually called 'highlevel vision' or 'late vision', object recognition is not bound to a viewer-centred coordinate system.

To make the position against which I intend to argue as strong as possible, I will assume a division between early and late vision that respects the traditional Marrstyle picture of visual information processing. ${ }^{8}$ Within this traditional hierarchical approach to vision, there is little question that the processing of information at the primal sketch level is a bottom-up process, encapsulated and isolated from any higher-level background cognitive state. Also uncontroversial is the claim that, in contrast, both the processing of information at the 3-D sketch level and the content of its output states are permeable to top-down influences from those background states, since late vision is indeed characterized as encompassing those aspects of visual perception that reflect influences from memory, context and knowledge. It is thus visual representation at the $2 \frac{1}{2}-\mathrm{D}$ sketch level that emerges as most relevant when discussing $C I$ vis-à-vis the content of the states of early vision; for the content of the primal sketch level representations could plausibly be considered subpersonal. Yet we typically experience, i.e., we are phenomenally aware of, colour, shape and texture-all properties represented at the $2 \frac{1}{2}-\mathrm{D}$ sketch level. EVS, it can now be further clarified, are the visual representational states that are characteristic of the 21/2-D sketch level.

As mentioned above in the Introduction, the claim that $E V S$ are cognitively impenetrable entails that there cannot be any direct causal influence from prior cognitive states on the content of EVS. A direct causal influence is taken to be a causal influence on the processing of input information that is not mediated by attention or by any prior cognitive (including affective) states. My belief that it is time to turn the oven off, for example, may influence what I see by causing me to move my eyes in the direction of the kitchen clock. Such an influence, however, is not taken to be direct in the sense relevant for $C I$; for in this case my belief determines only where I direct my attention, not what I see once I am looking there. CI means that pre-existing cognitive states can have no causal influence on the 
processing of input information (see e.g., Shea, forthcoming); it does not question that the input we end up processing is a result of what we attend to.

It is not just the role played by spatial attention that matters for making a causal influence indirect, in the sense that is relevant for $C I$; so-called feature/object-based attention (i.e., the attention we pay to particular features of objects, such as their colour) is also deemed to alter the content of our EVS only indirectly. The notion of indirect causal influence as it applies to feature/object-based attention, however, is anything but clear. The idea seems to be that, for prior representational or affective states to have an influence, we have first to recognize the object we are looking at; and object recognition does not take place until the 3D sketch level, which is already outside early vision. Neither spatial nor feature/object-based attention-considered to be indirect causal influences that occur, respectively, pre- and post-perceptually-is thus regarded as a threat to $C I$ (see e.g., Pylyshyn, 1999; Raftopoulos, 2009).

Last, but not least, semantic influences on $E V S$ are also ruled out when considering whether $C I$ is true or not. If $C I$ is true, there cannot be any direct causal influence on the content of EVS that is semantically or rationally related to the content of some prior representational or affective state. ${ }^{9}$ In other words, a case such as the following does not count as cognitive penetration: my belief that today is the day of an important exam causes me to experience some flashing lights as the result of my anxiety about the exam (Macpherson, 2012, p. 26). Even though my belief caused the apparent light flashes, the content of the belief and the content of the experience are not logically or rationally related. Putting together all these considerations, and adapting Siegel's (2012) but also Raftopoulos' own (2013) characterization of cognitive penetrability, $C I$ could be formulated as follows:

$C I$ : $E V S$ are cognitively impenetrable if and only if it is nomologically impossible for two subjects (or for one subject in different counterfactual circumstances, or at different times) to be in $E V S$ with different contents, as a result of differences in other cognitive (including affective) states, while seeing and attending to the same distal stimuli under the same external conditions. 
In what follows, I discuss whether the (assumed) $C I$ of $E V S$, understood as expressed in $C I$, is a sufficient and necessary condition for their content to be nonconceptual. ${ }^{10}$

\section{Philosophical qualifications and two versions of nonconceptualism}

Just to be absolutely clear, MET is a claim about representational states. Being representational, EVS are states with content. By being in an EVS with a particular content, the subject is thereby representing the world as being a particular way. The content of an EVS is specified, as is the content of any other kind of representation, by the conditions under which it would be true (veridical). Furthermore, EVS are conscious representational output states: their content is personal-level content. EVS thus represent properties of which we are phenomenally aware-with phenomenal awareness characterized along the lines of Block's classic (1995) notion of phenomenal consciousness. It thus seems appropriate to talk about EVS as visual experiences, even if each of them is "a 'fleeting' experience that lacks the sharpness of ordinary experience, on account of the fact that phenomenal contents lack spatial and temporal coherence" (Raftopoulos \& Müller, 2006, p. 208). As experiences, EVS would have phenomenal character-there would be something it is like for a subject to be in them. Raftopoulos explicitly claims $(2013$, p. 6):

I assume that early vision despite its being a pre-attentional stage of visual processing includes content at the phenomenal level, in addition to its subpersonal information processing content. One can have some sort of awareness, phenomenal awareness, of perceptual contents that are formed pre-attentionally.

There is, of course, a close relationship between the phenomenal character of a visual experience and its representational content. The discussion in this paper will remain neutral on whether that relation is one of supervenience or identity. Advocates of MET just claim that "perceptual states have a phenomenal character in virtue of having some kind of representational content" (Raftopoulos, 2009, p. 154). Here, I am thus only committed to the following pre-theoretically plausible claim: necessarily, two EVS with different phenomenal character have different contents. 
The meaning of 'nonconceptual' is a more controversial matter. There are two interpretations of the term (see e.g., Heck, 2000; Speaks, 2005; Tye, 2006). According to the first interpretation-which, following Heck's terminology, I call the state view - being nonconceptual (nonconceptual $\mathrm{s}_{\mathrm{s}}$ henceforth) is understood as a relational property between a subject's perceptual state and the content of that state. Content is nonconceptual $l_{\mathrm{s}}$ if and only if the subject who is in a perceptual state (at a time) need not possess (at that time) the concepts involved in its correct characterization.

According to the second interpretation — which again, following Heck's usage, I call the content view - being nonconceptual (nonconceptual $\mathrm{c}_{\mathrm{c}}$ henceforth) is considered to be a monadic property of the content of perceptual states. Since beliefs are, paradigmatically, states with conceptual content, the content view is often formulated as follows: the content of a perceptual state is nonconceptual $\mathrm{l}_{\mathrm{c}}$ if and only if it is different in kind from the content of beliefs. ${ }^{11}$ This difference in the kind of content can be characterized in a variety of ways. It may be that the content of belief is propositional, while perceptual content is not. Or it may be that both are propositional, but that belief content is structured while perceptual content is not-it is, e.g., a function from possible worlds onto truth values. Or it may be that the content of both belief and perception is propositional and structured, but the constituents of the propositions are Fregean senses in the case of belief and Russellian propositions in the case of perception (see e.g., Speaks, 2005).

Now, in his defence of $M E T$, Raftopoulos makes it very clear that the relevant contrasting notion of conceptual content in his account is Fregean. Hence, according to the target view, to claim that the content of $E V S$ is nonconceptual $\mathrm{l}_{\mathrm{c}}$ amounts to claiming that it is not composed of (Fregean) modes of presentation. ${ }^{12}$

MET thus admits two different readings depending on whether the CI of EVS is taken to be a necessary and sufficient condition for their content to be nonconceptual (MET-state) or nonconceptual $\mathrm{c}_{\mathrm{c}}(M E T$-content $)$. 
A subject need not possess the concepts involved in a correct characterization of the content of their $E V S, E$, if and only if $E$ is cognitively impenetrable.

\section{MET-content}

The content of a subject's $E V S, E$, is different in kind from the content of beliefs if and only if $E$ is cognitively impenetrable.

Interestingly, Raftopoulos explicitly rejects the distinction between the state and the content views of perceptual nonconceptualism. He does so for two reasons. The first is that "most accounts of NCC are better understood as referring to both contents and states" (Raftopoulos, 2013, p. 9). The second reason is "that it does not make much of a sense to talk about states without reference to the kind of content they have ...[because] the structure of contents must be reflected in the structure of their vehicles/states" (ibid.). However, it does seem appropriate to engage in critical analysis of $M E T$ along via these two different interpretations, since Raftopoulos repeatedly, especially throughout his (2013) paper, characterizes the property of being nonconceptual as a property that applies both to states of early vision and to their content. Here is yet another illustration of this (Raftopoulos, 2013, p. 8): ${ }^{13}$

... the existence of CI processes that extract information directly from the environment is both a necessary and sufficient condition for NCC. Thus, content $\mathrm{P}$ of a perceptual state $\mathrm{S}$ of $\mathrm{X}$ is such that the processes by virtue of which $\mathrm{X}$ is in $\mathrm{S}$ and has an experience as of $\mathrm{P}$ cannot, in principle, be affected directly by cognitive processes, if and only if $\mathrm{P}$ and $\mathrm{S}$ are nonconceptual; this is the $\mathrm{CI} \equiv \mathrm{NCC}$ thesis.

Furthermore, Raftopoulos' replies to possible objections to MET show very clearly which of the two interpretations he is relying on - as will become apparent in the next two sections. Hence, even if it turns out that the state and content views cannot ultimately be distinguished on a certain understanding of concepts and concept possession, it still makes sense, given the dialectics in this paper, to explore both interpretations with regard to $M E T$. 


\section{MET-state}

In this Section, I argue that MET is false when understood as MET-state, and offer a diagnosis of the confidence with which advocates endorse the thesis.

Let us begin with the sufficiency claim of MET-state: if an EVS, E, with content $p$ is cognitively impenetrable by a background state, then a subject need not possess the concepts, $C$, involved in a correct characterization of $p$. $C$ refers here to those concepts that are constitutive of the background cognitive state. Here is Raftopoulos on the matter (2013, p. 8, my italics):

The definition of the CI of early vision stipulates that early vision is not directly affected by cognitive states and, thus, its contents are conceptually encapsulated through top-down effects. Concepts can figure in early vision content either by being there from the beginning or by penetrating early vision content in a topdown manner ... The second possibility is excluded by my assumption that early vision is CI. All these together mean that one can be in an early vision state with some content without possessing or applying the concepts that should be used to describe the relevant content. It follows, in view of the standard definition of NCC, that this content is NCC. Thus, if some content is CI, it is NCC (the sufficiency claim).

I will focus on the second possibility, since: (i) I grant Raftopoulos that a notion of concept as hardwired in early vision - as is, e.g., Pylyshyn's (2007) notion of codes for proximal properties - is too theoretically alien to match the relevant notion in the nonconceptualism debate; and (ii) the first line of argument fits MET-content much better than MET-state and I will discuss it in the next section. What matters for my purposes here is Raftopoulos' argument in the second part of the quote in favour of the sufficiency claim. It is important to notice, first, how what is considered to be the standard definition of nonconceptualism here (see the text in italics) is precisely the standard definition that appears in MET-state, i.e., a definition based on the relation between a subject's possessing (or applying) a concept and its content. ${ }^{14}$ Second, and 
more important, the argument only works on the assumption that all and only early vision is cognitively impenetrable. This assumption is then taken to entail, without any further argument, that EVS could not be cognitively impenetrable and have conceptual content.

Now, to make the sufficiency claim false, it is not enough to show that subjects can have the relevant concepts while EVS remain cognitively impenetrable; that a subject need not possess the concepts, $C$, involved in a correct characterization of the content, $p$, of an $E V S, E$, does not entail that the subject cannot have those concepts. That a subject need not possess $C$ only rules out the subject's having to possess $C$ in order to be in $E$. So, let us assume that $E$ is cognitively impenetrable, so that no background cognitive state can directly causally affect $E$ in a way that alters $p$. Why would this claim be incompatible with the claim that the subject has to possess $C$ in order to be in $E$ ? A subject may need to possess certain conceptual capacities in order to be in $E$ with a particular content, $p$. And this is, at least on occasion, indeed the case precisely because the content of $E V S$, we are told, is personal-level content, and hence $p$ should play a role in the way having an experience with such content entitles us to a belief. And $E$ may not be able to play that role if the subject does not have the concepts involved in a correct characterization of $p$. Yet, in granting the need to exercise such conceptual capacities, we do not have to commit ourselves to their having any direct causal influence on $E$ in such a way as to change its content. In general, a subject's possession of $C$ may be constitutively required for their being in an $E V S, E$, with content $p$-because without $C, p$ could not play the rational role expected of personal-level content - even if $E$ is cognitively impenetrable. Therefore, the sufficiency claim of MET-state is false.

It looks as if behind the sufficiency claim of MET-state there is a rather nonstandard understanding of nonconceptual as being a causal rather than a constitutive relationship. State nonconceptualism (and thus the modal claim 'a subject $S$ need not possess the concepts $C$ involved in a correct characterization of the content, $p$, of their $E V S, E$ ') seems to be taken as equivalent to the claim ' $E$ could be tokened without $S$ 's having $C$ '. So, ' $S$ needs $C$ to be in $E V S E$ with content $p$ ' is interpreted as ' $E$ causally depends on $C$ for its tokening', thus ruling out the idea that $E$ could be cognitively impenetrable while its content is conceptual. However, state 
(non)conceptualism is not a claim about the causal independence between a subject's states and their content. Rather, it is a claim about what is (or is not) constitutively required of a subject in order for them to count as being in a state with a particular content - the appropriate kind of personal-level content. So, the $C I$ of an EVS, E, is perfectly consistent with the requirement that $S$ possesses the relevant conceptsthose concepts, $C$, without which $E$ could not play the functional role that is distinctive of a state with personal-level content. This also shows, interestingly, that if being nonconceptual is construed as a causal instead of a constitutive relationship, the claim that the content of $E V S$ is nonconceptual will be tantamount to claiming that EVS are informationally encapsulated; and that, as we know, is equivalent to claiming that $E V S$ are cognitively impenetrable. So, were we to understand the sufficiency claim of MET-state in causal terms, that claim would be true, but trivially so.

What about the necessity claim of MET-state? If a subject need not possess the concepts, $C$, involved in a correct characterization of the content, $p$, of their $E V S, E$, then $E$ is cognitively impenetrable. Here again is Raftopoulos' argument, this time, in favour of the necessity claim $(2013$, p. 8$)$ :

Burge's and Martin's discussions of NCC emphasize the extraction of information from the environment through direct causal links without conceptual involvement as a necessary condition for NCC. This requires a perceptual stage that extracts information from the world in conceptually unmediated ways. A perceptual stage that extracts information in conceptually unmediated ways is a stage of visual processing that is CI. This intuitively leads to the view that NCC is the content of perceptual states that are CI. In other words, if some content is nonconceptual, it is CI (the necessity claim).

The necessity claim would thus turn out to be false if we could show that $S$ need not possess $C$, and yet $E$ is cognitively penetrable. As before, it is important to keep in mind that not needing to possess $C$ does not entail that the subject does not possess them; it only rules out the subject's having to possess such concepts. To illustrate that just such a situation may obtain, Bermúdez and Cahen (2012) appeal to Tye's (1995; 2000) analysis of our visual experiences of ambiguous figures such as the duck/rabbit. Tye's view, they contend, allows for situations in which a subject would have a 
disambiguated visual experience of an ambiguous figure-let us say, they would experience the duck/rabbit as a rabbit — as a result of having deployed the concept rabbit. The experience would thus be cognitively penetrable. Yet, the subject did not have to possess the concept rabbit to undergo an experience with the same content, so the content of their experience is nonconceptuals. Here is Tye $(1995$, p. 140) on this issue:

Where a figure has an ambiguous decomposition into spatial parts, concepts can influence which decomposition occurs. This is one way in which top-down processing can make a phenomenal difference. But once a particular decomposition is in place, the way in which an ambiguous figure phenomenally appears is fixed. . the concepts do not enter into the content of the sensory representation and they are not themselves phenomenally relevant.

In general, the phenomenal character and hence (for a representationalist like Tye) the content, $p$, of an EVS, E, may very well be the same regardless of whether the subject possesses the concepts, $C$, involved in a correct characterization of $p$ or not. Therefore, the necessity claim of MET-state seems to be false.

The standard rejoinder to this objection appeals to the role of spatial attention, as discussed in Section 2 above. Raftopoulos (2013, pp. 11-14) develops it along the following lines. Tye's analysis does indeed allow for top-down causal influence of concepts on the disambiguated experiences of an ambiguous figure; but $C I$ is consistent with such a top-down influence because the causal influence here is not direct, it only affects the phenomenal character of what is perceived by determining first, through attention, which of the two figures we perceive:

What one chooses to attend to may be determined by cognitive factors, but this type of attentional modulation occurs before the operation of early vision and does not directly causally affect early vision. (Raftopoulos, 2013, p. 13)

The content of disambiguated perceptual states is the result of the role that concepts play in determining where we first fix our attention. Their influence is thus indirect, occurs pre-perceptually, and poses no threat to $C I .^{15}$ 
The difficulty with this rejoinder is twofold. First, it seems again to presuppose a causal understanding of the property of being nonconceptual. Otherwise, were we to interpret the antecedent clause of the necessity claim along the required statenonconceptualist lines - a subject $S$ need not possess the concepts involved in a correct characterization of the content of their EVS - nothing would follow regarding the direct or indirect causal influence exerted by those putative concepts that $S$ can have, even if $S$ need not have them. In other words, the antecedent in the necessity claim of MET-state is a conceptual statement, and as such, its truth does not entail that any purported causal influence from the relevant cognitive states on a subject's EVS is direct or indirect. The entailment would only follow if 'nonconceptual' was treated, in this context, as synonymous with 'conceptually encapsulated', i.e., with 'cognitively impenetrable' - as the notion is defined in $C I .{ }^{16}$

Second, remember that we are trying to assess whether it is the case that if subjects need not possess the concepts involved in a correct characterization of the content of their EVS, then EVS are cognitively impenetrable. Obviously, putative counterexamples would be situations in which EVS are cognitively penetrable by concepts, which subjects need not possess in order to have such experiences, but which they do possess - otherwise the issue of $C I$ would not even arise. We are told that cases such as the disambiguated perception of ambiguous figures are not counterexamples to the necessity thesis because the causal influence of the concepts invoked is not a direct causal influence. Furthermore, a notion of cognitive penetrability that allows for such an indirect influence of the relevant conceptsRaftopoulos calls it "the intuitive notion of CP" (Raftopoulos, 2013, p. 13)—ought to be dismissed. However, if we stick to the technical notion of $C I$, the causal influence of concepts in perception will always be indirect. All putative counterexamples to the necessity claim of MET-state, such as the case of ambiguous figures, will necessarily be cases in which the subject's perceptual experiences will absorb and conceal whatever phenomenal character the output states of early vision processing, i.e., EVS, may have. That is because the perceptual experience of, e.g., an unambiguous figure necessarily involves object recognition, and object recognition takes place at the late stage of visual information processing. There will be no output states of early vision processing that are not, immediately and without leaving any phenomenal trace, 
turned into the input states of late vision processing, according to this picture. Insofar as EVS are the output states of early vision processing, those states seem to have been left void of any phenomenal character. The "indirectness of attention" strategy thus seems to belie the claim that we are phenomenally aware of the properties represented by $E V S$.

\section{MET-content}

In this section I examine $M E T$ understood as a claim about the relationships between the $C I$ of EVS and the kind of content such experiences have: MET-content. Remember that according to MET-content: the content of a subject's $E V S, E$, is different in kind from the content of beliefs if and only if $E$ is cognitively impenetrable.

A methodological caveat is in order here. As I pointed out in Section 3, by considering the Fregean view to be the relevant account of conceptual content in the present context, I only restrict the array of possible counterexamples to $M E T$, thus shoring it up against relatively easily dismissible objections. ${ }^{17}$ It may thus help to keep in mind the following, more specific characterization of MET-content: the content of a subject's $E V S, E$, is different in kind from the content of beliefs, i.e., it is not composed of Fregean modes of presentation, if and only if $E$ is cognitively impenetrable.

Raftopoulos' line of argument is pretty straightforward with regard to the sufficiency claim of MET-content: to assume, first, that early vision is cognitively impenetrable; to argue, second, that no concepts are already built in the early vision system. If early vision is cognitively impenetrable and concepts do not directly influence $E V S$, and the early vision system does not contain concepts, then "concepts do not enter early vision in a top-down manner. As a result, concepts do not exist in the contents of early vision, which means that these contents are not conceptually structured; the content of early vision is NCC" (Raftopoulos, 2013, p. 14). In other words, if early vision is cognitively impenetrable, then the content of early vision is not Fregean. 
Agreeing with Raftopoulos comes easily in terms of rejecting the idea that an appeal to hardwired concepts in early vision could be considered a good case against the sufficiency claim of MET-content. 'Concepts' in this sense would not be the kind of entities to which MET-content refers. However, there does not seem to be any reason why EVS could not be cognitively impenetrable and thus free of any direct causal influence from concepts while their content is Fregean content. It does not seem inconsistent — and it may even be plausible — to hold that the content of EVS is composed of (perhaps indexical) Fregean modes of presentation, while at the same time endorsing the truth of $C I$. Modes of presentation, as the notion is applied in the analysis of experience, are the ways objects and properties look to us, as opposed to the ways objects and properties are given to us in thought. Modes of presentation, importantly, need not be explicitly represented by the subject. ${ }^{18}$

David Chalmers' $(2004$; 2006) account of phenomenal content could be considered to be a view along these lines. He argues that visual experience has both Fregean and non-Fregean-Russellian or unstructured - content; yet, it is the mode of presentation that captures the phenomenology and hence the phenomenal character of experience, while the (imperfect, in Chalmers' account) veridicality of experiences depends on non-Fregean content. This, of course, is not the place to try to sum up Chalmers' complex two-dimensionalist account of phenomenal content; or to endorse it. However, if we can draw upon the idea of the mode of presentation of objects and properties in experience to capture the phenomenal character of $E V S$, and if such modes of presentation can also be the key notion in characterizing the content of conceptual states such as beliefs, then it is not the case that the (alleged) CI of EVS necessarily establishes that their content is nonconceptual, , i.e., it is not the case that the (alleged) CI of EVS necessarily establishes that they do not have the same content as beliefs.

According to a view such as this, the content of an EVS, E, when I see and attend for example to the redness of a cut-out heart shape with colour $\mathrm{R} / 4 / 12$, is the way the colour R/4/12 appears to me. This mode of presentation introduces a constraint on the conditions of satisfaction of my experience by making $\mathrm{R} / 4 / 12$ the property represented by my EVS. The mode of presentation can be understood as the property 
that normally causes phenomenally red R/4/12 experiences (see Chalmers, 2004, pp. 172-173). Yet, appealing to Fregean concepts of this kind does not entail that there is any direct top-down causal influence of the relevant concepts (i.e., the concept red, the concept red $\mathrm{R} / 4 / 12$ or any demonstrative concepts) on the content of $E$. The content of EVS would then be, as the content of belief is, conceptualc: composed of Fregean modes of presentation; but the relation between a subject's $E V S$ and their content would be nonconceptuals. Here is Chalmers on this idea (2006, p. 122):

These nonconceptual Fregean contents need not themselves be a different sort of object from conceptual Fregean contents. For example, it could be that an experience as of a red object and a belief that completely endorses it have the same Fregean content. Instead, one might say that the Fregean content of perception involves a nonconceptual content relation: the relation that associates perceptual states with their Fregean contents is such that subjects need not possess the relevant concepts in order for their states to have the relevant content.

The motivation for a view such as this stems from our pre-theoretical

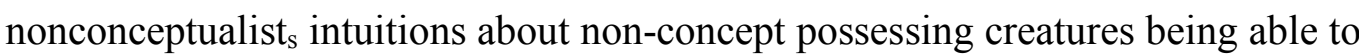
undergo visual experiences with phenomenal character and conditions of satisfaction, while also allowing for the conceptualist ${ }_{c}$ view that the world, as we perceive it, is always conceptualized, i.e., it always appears to us under a particular mode. The properties and objects themselves can only be found in a world in which how things appear to us is always and exactly how things are. Our experiences, in contrast, are always the result of complex contingent causal chains between the objects and properties that we perceive, and how we represent them in experience. Fregean modes of presentation would capture the phenomenal character of our $E V S$, albeit imperfectly, because there could always be differences due for example to optical illusions. According to this view, the content of EVS is the same conceptual content as the content of beliefs. The only difference is whether subjects need to possess the relevant concepts or not, i.e., whether or not the relation of subjects' EVS to such content is conceptual $\mathrm{s}_{\mathrm{s}}$ or nonconceptual $\mathrm{s}$.

Let me now move on to examine the necessity claim of MET-content. Raftopoulos' strategy consists of first characterizing nonconceptual content- 
understood as content that is not conceptually structured-as content that "is retrieved in a stage of visual processing that is CI" (Raftopoulos, 2013, p. 2). He relies heavily on vision science for this purpose and provides a detailed account of the nature of information processing in early vision in terms of a feedforward sweep in which the only signals that intervene are transmitted bottom-up with no influence whatsoever of signals from higher-level cognition. This account highlights the timing of the processing of information, which is taken to last around just 120 milliseconds. The content of the output states of such bottom-up processing of visual information is regarded as (purely) nonconceptual content. From this characterization, Raftopoulos concludes, "[t]hus, if some content is purely NCC, it is CI" (ibid.). The idea thus is that if some content - the content of EVS - is not conceptually structured, then it is cognitively impenetrable. Given the constraints on concepts discussed above, the necessity claim of MET-content amounts to the following: if the content of EVS is not composed of Fregean concepts, then EVS are cognitively impenetrable.

The necessity claim would thus be false if the content of EVS was not composed of Fregean concepts, but EVS were nevertheless cognitively penetrable. Such a view, which resembles some of the ideas put forward by Evans (1982) with regard to the content of perceptual experience, seems again not only to be consistent but also plausible. In Evans' account, the result of visual information processing can be considered to be the personal-level nonconceptual ${ }_{c}$ content of visual states only if it feeds into a concept-possessing creature: a creature already capable of deploying the conceptual apparatus of reasoning. Otherwise, such visual states would just be considered the informational states of subpersonal mechanisms (Evans, 1982, pp. 124 $\& 158$ ). The content of EVS could be characterized in non-Fregean terms (as, e.g., Russellian or unstructured propositions, i.e., as structured or unstructured sets of objects and their properties) but that does not seem to rule out the nomological possibility that two subjects with the same visual faculties, looking at and attending to the same distal stimulus, could have different EVS as a result of whether or not they possess the relevant concepts - or whether they possess any concepts at all.

Part of the motivation for a view such as this relates to some of the considerations examined above with regard to the sufficiency thesis of MET-content. Creatures that possess no concepts at all could still be in visual informational states with 
nonconceptual, sub-personal content. However, to claim that a creature is in a visual informational state, $V$, with nonconceptual content $p$ need not entail that the creature undergoes an $E V S, E$, with such content. For $V$ to count as an $E V S$, it is also necessary, according to this view, that "it serves as the input to a thinking, conceptapplying, and reasoning system" (Evans, 1982, p. 157). Even if Evans himself does not require that the concepts a reasoning creature must possess are exactly the same concepts involved in $p$, a position such as his remains viable and hence shows that the claim that the content of EVS is nonconceptualc, does not necessarily entail that EVS are cognitively impenetrable.

Since both the sufficiency and the necessity claims of MET-content turn out to be false, and since it is only on this reading of MET that $C I$ could be used to settle the issue of what type of content $E V S$ have, I conclude that that $C I$, on its own, falls short of settling the nature of their content.

\section{Conclusion.}

If the arguments put forward in this paper are sound, $M E T$ is false on either standard interpretation of 'nonconceptual' and hence there is no philosophical interpretation of the thesis according to which the (alleged) $C I$ of EVS is a necessary and sufficient condition for EVS and their content to be nonconceptual. MET could only be true according to some non-standard, causal interpretation of the notion of nonconceptual content — one which makes 'nonconceptual' and 'cognitive impenetrable' not only coextensive but synonymous. Yet, on that reading, the thesis would either be trivially true or would entirely fail to engage with the contemporary literature on perceptual nonconceptualism.

\section{Acknowledgments}

Research for this paper was supported by the Spanish government via research grants MCINN FFI2011-26853 and CSD2009-0056 (CONSOLIDER INGENIO), and by the Catalan government via research grant GRECC 2009SGR1528. 
$1 \quad$ I provide more precise definitions of both theses below.

2 Although in Raftopoulos' (2013) paper 'NCC' is meant to refer to 'nonconceptual content', sometimes, as in this quote, 'NCC' just means 'nonconceptual'.

3 For Raftopoulos, the states of early vision only have nonconceptual content, unlike the states of late vision, which can have both conceptual and nonconceptual content. In what follows, I will take it for granted that all talk about nonconceptual content is talk about purely nonconceptual content. I will hence omit the adverb 'purely'.

4 This is, however, the interpretation that seems to lie beneath some of the arguments in favour of MET. See Section 4.

5 See e.g., Raftopoulos and Müller, 2006, § 3 and especially Raftopoulos (2013).

6 I use 'state' in a broad sense to include events, since experiences are technically events and not states. Nothing in my argument hinges on this distinction.

7 For Marr, the $2 \frac{1}{2}$-D sketch level was a specific hypothesis about the abstract task analysis involved at this intermediate level of visual processing. Much of contemporary vision science, although deeply influenced by Marr's work, has abandoned the posited 21/2-D sketch level as a working hypothesis in the search for the exact nature of these, still acknowledged, mid-level representations.

8 It may be that an alternative way of understanding the nature of visual information processing, such as the predictive coding hypothesis, yields a more porous picture of the relations between early and late vision (see e.g., Friston, 2010; Friston \& Stephan, 2007). I will ignore this aspect of the debate here, since, as I say, it would only weaken the position against which I argue.

9 This semantic/rational constraint lies at the heart of standard definitions of cognitive penetrability. See e.g.: "if a system is cognitively penetrable then the function it computes is sensitive, in a semantically coherent way, to the organism's goals and beliefs, that is, it can be altered in a way that bears some logical relation to what the person knows" (Pylyshyn, 1999, p. 343).

10 Raftopoulos often talks about the $C I$ of both the states of early vision and their content, and sometimes he just talks about the $C I$ of the content of early vision (as, e.g., in the title of the paper). I simplify matters and talk about the CI of EVS thus encompassing both aspects, for the very notion of $C I$ requires the content relation. Since I grant this part of $M E T$, nothing hinges on this simplification. I also take cognitive states to always include affective states.

11 Of course, if content is characterized in terms of functions from possible worlds to truth-values, then beliefs will not involve concepts either (see e.g., Stalnaker, 1998). However, the view that is important to consider in this context entails that there is a contrast between the (Fregean) content of belief and the content of perception. See below for further elaboration.

12 Note that interpreting 'conceptual content' in the restrictive sense of 'Fregean content' is a substantial thesis that needs independent support. For my present purposes, however, it suffices to say that: (i) this is how the notion is understood by the advocates of $M E T$; and (ii) being more 
restrictive about what counts as conceptual content makes MET more immune to

counterexamples - especially counterexamples to the sufficiency claim. I will therefore adhere to the Fregean reading so as to avoid making MET too easily refutable.

13 See the first quote in the Introduction for another formulation of this type.

14 Here is another definition of nonconceptual content (NCC) provided by Raftopoulos that clearly fits the state view of nonconceptualism: “According to the standard definition of NCC, a person's state $\mathrm{S}$ with content $\mathrm{p}$ has NCC iff the person need not possess or apply the concepts used to characterize p" (Raftopoulos, 2013, p. 9)

15 See also Raftopoulos (2011). For discussion, see e.g., Macpherson (2012).

16 See e.g., Raftopoulos and Müller, 2006, p. 190: "the notion of 'nonconceptual content' ... is defined as the content that is retrievable from a scene through the cognitively encapsulated processes of perception." $C I$ and state-nonconceptualism about EVS would thus be, on this causal reading, not only mutually entailing but conceptually equivalent claims.

17 To wit, it would be relatively straightforward for the advocates of MET to disregard as counterexamples to the sufficiency thesis positions that involved non-Fregean notions of content, i.e., content seen as Russellian propositions or functions from possible worlds to truth values. It could be argued that these non-Fregean notions are not suitable for securing the necessary link between the ways a subject takes the world to be in experience and the abilities that count in an explanation of the subject's intentional behaviour (see Toribio, 2008). By making conceptual content Fregean content, the sufficiency claim becomes more challenging. It is also how Raftopoulos understands the dialectics here, explicitly (see, e.g., his 2013, p. 2).

18 Raftopoulos claims at some point that "perception has NCC, which is ... neo-Fregean" and adds: "Let me dwell on my characterization of perceptual content as neo-Fregean content. Fregean content involves modes of presentation (mops) in thought and, thus, by definition is conceptual content. In this sense, NCC cannot be Fregean content ...To distinguish NCC and its mops from the standard conceptual Fregean mops, I use the term 'neo-Fregean'.” (Raftopoulos, 2013, p. 2, my italics) It is important to note, however, that 'neo-Fregean' has a clear, standard meaning in debates about the nature of the content of mental representations. Neo-Fregean content is Fregean content in which the abstract, objective and non-psychological nature of content that the original Fregean account requires is substituted for the idea of contents as ability types - also objective, non-psychological and abstract. Yet, the instantiation of such ability-types just consists of the set of abilities that subjects exercise when they entertain thoughts. A neo-Fregean account of content, in other words, treats content as conceptual. It is thus rather misleading to use the expression 'neoFregean' in this context to mean 'not Fregean', i.e., nonconceptual. Nevertheless, I suppose anyone could - just by stipulation, as Raftopoulos does — decide to use 'neo-Fregean' in this rather counterintuitive, non-standard way. The point of my criticism remains, since I am trying to show that there is a Fregean account (in fact, it would be neo-Fregean, in the standard sense) of the content of perception - Chalmers' - that can be used as a plausible counterexample to the sufficiency claim of MET-content. 


\section{References}

Bermúdez, J. \& Cahen, A. (2011). Nonconceptual Mental Content. The Stanford Encyclopedia of Philosophy. Ed. E.N. Zalta. URL = http://plato.stanford.edu/archives/sum2011/entries/content-nonconceptual/.

Block, N. (1995). On a confusion about a function of consciousness. Behavioral and Brain Sciences, 18, 227-287.

Byrne, A. (2005). Perception and conceptual content. In E. Sosa \& M. Steup (Eds.), Contemporary debates in epistemology (pp. 231-250). Oxford: Blackwell.

Chalmers, D. J. (2004). The Representational Character of Experience. In B. Leiter (Ed.), The Future for Philosophy (pp. 153-181). Oxford: Oxford University Press.

Chalmers, D. J. (2006). Perception and the fall from Eden. In T. Gendler \& J. Hawthorne (Eds.), Perceptual Experience (pp. 49-125). Oxford: Oxford University Press.

Crane, T. (1992). The nonconceptual content of experience. In T. Crane (Ed.), The Contents of Experience (pp. 136-157). Cambridge: Cambridge University Press.

Evans, G. (1982). The varieties of reference. Oxford: Clarendon Press.

Fodor, J. (1983). Modularity of mind. Cambridge, MA: MIT Press.

Friston K. (2010). The free-energy principle: a unified brain theory? Nature Reviews Neuroscience 11 (2), 127-138.

Friston, K., \& Stephan, K. E. (2007). Free-energy and the brain. Synthese, 159(3), $417-458$. 
Heck, R. (2000). Nonconceptual content and the 'space of reasons'. The Philosophical Review, 109(4), 483-523.

Heck, R. (2007). Are there different kinds of content? In J. Cohen \& B. McLaughlin (Eds.), Contemporary Debates in Philosophy of Mind (pp. 117-138). Oxford: Blackwell.

Macpherson, F. (2012). Cognitive penetration of colour experience: rethinking the issue in light of an indirect mechanism. Philosophy and Phenomenological Research 84 (1), 24-62.

Pylyshyn, Z. (1980). Computation and cognition: issues in the foundations of cognitive science. Behavioral and Brain Sciences 3, 111-132.

Pylyshyn, Z. (1984). Computation and cognition. Cambridge, MA: MIT Press.

Pylyshyn, Z. (1999). Is vision continuous with cognition? The case for cognitive impenetrability of visual perception. Behavioral and Brain Sciences 22, 341-365.

Pylyshyn, Z. (2007). Things and places: How the mind connects with the world. Cambridge, MA: MIT Press.

Raftopoulos, A. (2009). Cognition and perception: how do psychology and neuroscience inform philosophy. Cambridge, Mass: MIT.

Raftopoulos, A. (2011). Ambiguous figures and representationalism. Synthese 181, 489-514.

Raftopoulos, A. (2013). The cognitive impenetrability of the content of early vision is a necessary and sufficient condition for purely nonconceptual content. Philosophical Psychology, DOI:10.1080/09515089.2012.729486.

Raftopoulos, A. \& Müller, V. (2006). The phenomenal content of experience. Mind and Language 21 (2), 187-219. 
Shea, N. (forthcoming). Distinguishing top-down from bottom-up effects. In S.

Biggs, M. Matthen, \& D. Stokes (Eds.) Perception and Its Modalities. Oxford:

OUP.

Siegel, S. (2012). Cognitive penetrability and perceptual justification. Nô̂s, 46 (2), 201-222.

Speaks, J. (2005). Is there a problem about nonconceptual content? The Philosophical Review, 114(3), 359-398.

Stalnaker, R. (1998). What might nonconceptual content be? In E. Villanueva (Ed.), Concepts (pp. 339-352). Atascadero, CA: Ridgeview Press.

Toribio, J. (2008). State versus Content: The Unfair Trial of Perceptual Nonconceptualism. Erkenntnis, 69(3), 351-361.

Tye, M. (1995). Ten problems of consciousness. Cambridge, MA: MIT Press.

Tye, (2000). M. Consciousness, color, and content. Cambridge, MA: MIT Press.

Tye, M. (2006). Nonconceptual content, richness, and fineness of grain. In T.

Gendler \& J. Hawthorne (Eds.), Perceptual experience (pp. 504-530). Oxford: Oxford University Press. 